\title{
Conference Paper \\ Harnessing Solar Energy for Every Home: Energy Saving Applications
}

\author{
Jitisha Aggarwal ${ }^{1}$ and M. L. Aggarwal ${ }^{2}$ \\ ${ }^{1}$ Electronics Engineering Department, YMCA University of Science \& Technology (State Government University), \\ Faridabad, Haryana 121 006, India \\ ${ }^{2}$ Mechanical Engineering Department, YMCA University of Science \& Technology (State Government University), \\ Faridabad, Haryana 121 006, India
}

Correspondence should be addressed to Jitisha Aggarwal; jitisha27@gmail.com

Received 19 December 2013; Accepted 19 February 2014; Published 10 April 2014

Academic Editors: R. K. Shivpuri and G. N. Tiwari

This Conference Paper is based on a presentation given by Jitisha Aggarwal at "National Conference on Advances in Materials Science for Energy Applications" held from 9 January 2014 to 10 January 2014 in Dehradun, India.

Copyright (C) 2014 J. Aggarwal and M. L. Aggarwal. This is an open access article distributed under the Creative Commons Attribution License, which permits unrestricted use, distribution, and reproduction in any medium, provided the original work is properly cited.

\begin{abstract}
Most of the present day resources of energy are limited and irreplaceable. The next generation will face acute energy crisis if alternate resources of energy are not developed concurrently. Increasing cost and import of conventional resources have bad effect on the economy of a country, and the only cheaper solution is "unlimited power" from the sun. The use of solar energy is so far limited in household applications. In fact, if we harness only 0.0034 percent of the solar energy reaching the Earth's surface, the energy need of the whole world will be met. In the present work, a substitute of 10-watt conventional night lamp has been proposed by a solar night lamp of the same light intensity through an experimental setup. The developed solar system is cheaper, portable, user friendly, and free from maintenance. The paper stresses on the need of replacement of conventional night lamp by solar night lamp in every home for reducing the energy crisis at present.
\end{abstract}

\section{Introduction}

Scarcity and cost of fossil fuels combined with their greenhouse gas emissions make the development of nonfossil fuel based methods of transportation a high-priority task. This interest was further fueled by world apprehensions concerned with nuclear wastes and nuclear safety on one hand and global warming on the other hand $[1,2]$. These considerations make solar energy the ultimate strategic choice as a source of world energy. As a result of current day satellite technology, designers now have a more or less clear picture about solar energy intensity distribution worldwide. Solar energy research emphasis over the past three decades was concentrated on two main aspects of this subject. The first is concerned with solar energy direct heat production and the second is involved with solar energy electricity production. Recent technological developments in thin-film photovoltaics, such as amorphous silicon [1, 2] and hybrid dye-sensitized/photovoltaic (PV) cells, are leading to new generations of consumer portable solar arrays. These new arrays are lightweight, durable, and flexible and have been reported to achieve power efficiencies of up to $10 \%$ [3].

There are many types of solar power lights that can be used to illuminate your home and surrounding and at the same time save the natural resources. These lighting systems will not only save electricity but also cause less pollution, by emitting less amounts of heat when compared to conventional lighting sources like bulbs. Solar lantern lights are extensively used for indoor lighting. All of the solar lighting devices used for indoor lighting need to be charged when sunlight is available and used during night time.

Home lighting systems are powered by solar energy using solar cells that convert solar energy (sunlight) directly to electricity. The electricity is stored in batteries and used for 
TABLE 1: Details of parts of night solar lamp.

\begin{tabular}{|c|c|c|c|c|}
\hline Serial number & Part name & Specification & Size & Cost \\
\hline 1 & Rechargeable battery & $3 \mathrm{~V}$, general & $5 \mathrm{~cm} \times 2 \mathrm{~cm}$ & Rs. 30 \\
\hline 2 & Solar panel (collector) & Photovoltaic (PV) cells & $5 \mathrm{~cm} \times 4 \mathrm{~cm}$ & Rs. 35 \\
\hline 3 & LED & $20 \mathrm{~mA}$ and $3 \mathrm{~V}$ (2 numbers) & $1.5 \mathrm{~cm} \times 0.5 \mathrm{~cm}$ & Rs. 5 \\
\hline 4 & Switch & Plastic, 12 V, O.5 A & $1.5 \mathrm{~cm} \times 0.5 \mathrm{~cm}$ & Rs. 5 \\
\hline 5 & Glass on LED to form lamp & General thin glass & $9 \mathrm{~cm} \times 6 \mathrm{~cm}$ & Rs. 10 \\
\hline 6 & Bottom plastic box & Light flexible thermoplastic material & $9 \mathrm{~cm} \times 5 \mathrm{~cm}$ & Rs. 10 \\
\hline 7 & Others: diode and connecting wires & - & Negligible & Rs. 10 \\
\hline
\end{tabular}

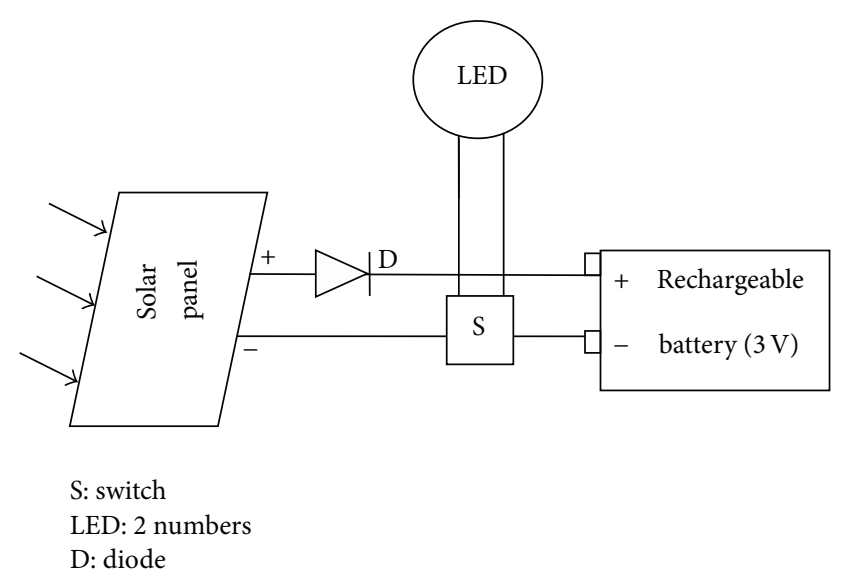

FIGURE 1: Circuit diagram for solar power light.

the purpose of lighting whenever required. These systems are useful in nonelectrified rural areas and as reliable emergency lighting systems for important domestic, commercial, and industrial applications. Though a lot of work has been done on solar energy, its commercial utility of small size, portable, and cheaper solar devices for every home has not been in use so far. The present work demonstrates experimentally tested portable solar energy system for every home for saving the energy of the country.

\section{Materials and Method}

The system comprises solar panel, rechargeable battery, LED, glass, switch, resistance, and diode (Figure 1). The overall size of portable solar night lamp is $12 \mathrm{~cm} \times 9 \mathrm{~cm}$, the total weight is $100 \mathrm{gm}$, and the total manufacturing cost is Rs. 105. LED, glass cover on LED, and solar panel are kept outside, while all other components are enclosed in a plastic box. The cost, specification, and size of various equipment are shown in Table 1.

The system in Figure 1 was designed to give a daily working time of 6-7 hours with the fully charged battery. The system provided for buffer storage for 4-5 nonsunny/cloudy days. The solar night lamp (Figure 2) had been working for the last six months and is still working without any maintenance.

Electricity generated from thermal power station is an expensive source of electricity; solar energy has turned it into

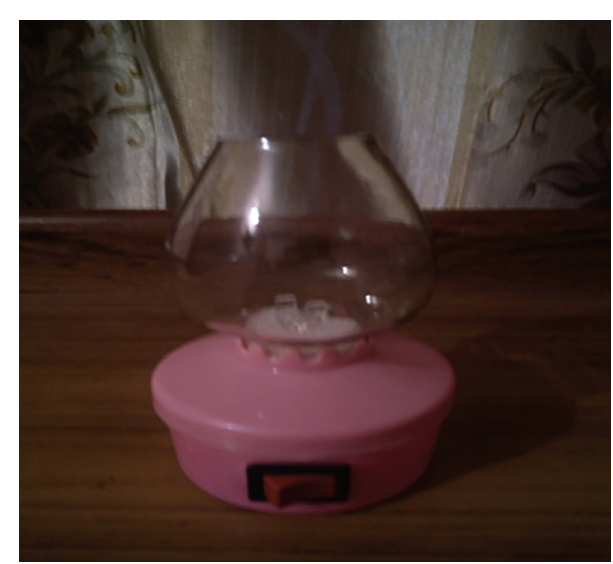

FIGURE 2: Solar night lamp for commercial applications.

an economical power source in the long-run. The amount of electricity generated from solar energy depends upon the available sunlight.

\section{Results and Discussion}

Conventional Electric Energy Consumption of Night Electric Lamp in a City (Energy Provided by Thermal Power Station). The energy consumption during night for two electric lamps of $10 \mathrm{~W}$ each in a house is $2 \times 10=20 \mathrm{~W}$. Let us assume that the number of houses in a city is 50000, the energy consumed by one house in a year is $(20 \times 8 \times 365) / 1000=58.4 \mathrm{KWh} / \mathrm{Yr}$, the yearly electricity bill of one house is $58.4 \times 6=$ Rs. 350.4 , the energy consumed by 50000 houses in the city in a year is $58.4 \times 50000=2920000 \mathrm{KWh} / \mathrm{Yr}$, and the yearly electricity bill of 50000 houses is $2920000 \times 6=$ Rs. $17520000=1.752$ crore.

Solar Energy Consumption of Night Solar Lamp in a City with the Same Light Intensity. The initial cost of one solar lamp is Rs. 105; the commercial price of the solar equipment (including taxes, sales, and marketing cost) is Rs. 150. Assuming that the life of solar equipment is one year (it is expected to be more), the cost of 50000 solar night lamps ( 2 in each house) is $150 \times 2 \times 50000=$ Rs. $15000000=1.50$ crore. The operational unit cost of the electricity is nil.

Comparison. Saving in the energy consumed from conventional thermal power station, hence, by 50000 houses in 
the city in a year is equal to $2920000 \mathrm{KWh} / \mathrm{Yr}$, because these houses are getting energy from solar night lamps; the yearly saving of cost using solar night bulbs for 50000 houses is $1.752-1.50=$ Rs. $0.252 \mathrm{cr}$; the yearly saving of cost using solar night bulb for one house is $350.4-150 \times 2=$ Rs. 50.4 .

Other Benefits of Solar Power Lights. The biggest advantage of using solar power is that it is an inexhaustible source of energy. Once you have installed the system, you do not have to worry that you would ever be without electricity, because the sun is always going to be there. The next advantage of using solar energy is that it does not emit any pollution into the environment. Solar panels do not release any emissions into the atmosphere while generating electricity. In the most remote locations, solar energy is the ideal source of electricity. A big advantage of solar energy systems is that a properly installed system does not require much maintenance.

\section{Conclusions}

It was established by testing the system during the last six months that if charged for 6-7 hrs in summer sunlight, the battery is capable of supplying stored energy to solar night lamp for 4-5 nights. The developed solar system is costing Rs. 150 only, portable, user friendly, and free from maintenance. It is established that there is need for replacement of conventional night lamp by solar night lamp in every home for the cheaper unit cost as well as solution of energy crisis at present.

\section{Conflict of Interests}

The authors declare that there is no conflict of interests regarding the publication of this paper.

\section{References}

[1] G. Danese, F. Leporati, R. Lombardi, M. Nucita, G. Pedrazzini, and G. Ricotti, "A profile in NiCd and $\mathrm{NiMH}$ batteries instrument for the characterization of voltage and temperature," in Proceedings of the 23rd Euromicro Conference, pp. 178-183, September 1997.

[2] M. Gonzalez, F. J. Ferrero, J. C. Anton, and M. A. Perez, "Considerations to improve the practical design of universal and full-effective NiCd/NiMH battery fast-chargers," in Proceedings of the 14th annual Applied Power Electronics Conference and Exposition (APEC '99), vol. 1, pp. 167-173, March 1999.

[3] M. Gonzalez, M. A. Perez, J. C. Campo, and F. J. Ferrero, "Accurate detection algorithm of battery full-capacity under fastcharge," in Proceedings of the IEEE Instrumentation and Measurement Technology Conference (IMTC '98), vol. 2, pp. 755-759, May 1998. 

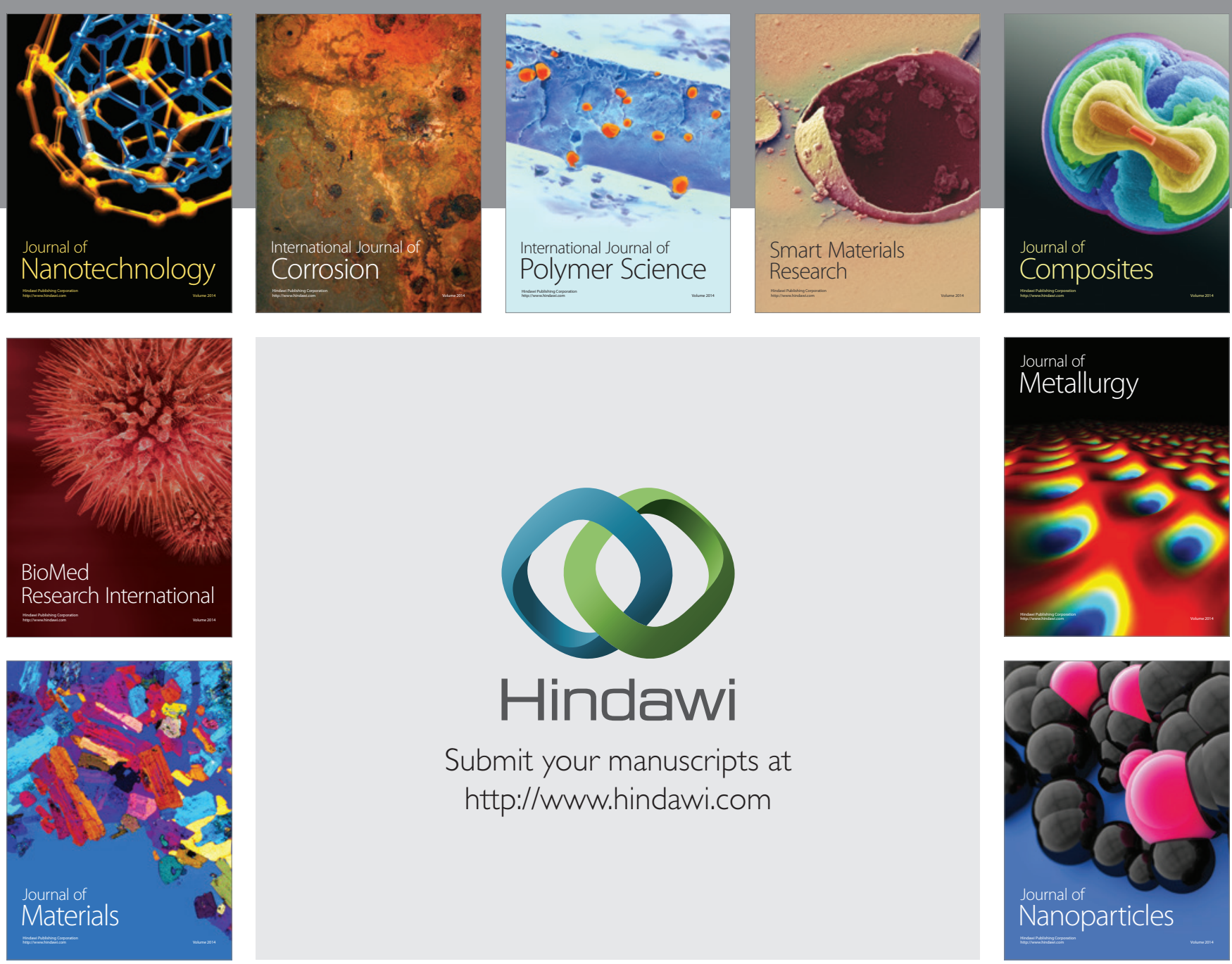

Submit your manuscripts at http://www.hindawi.com
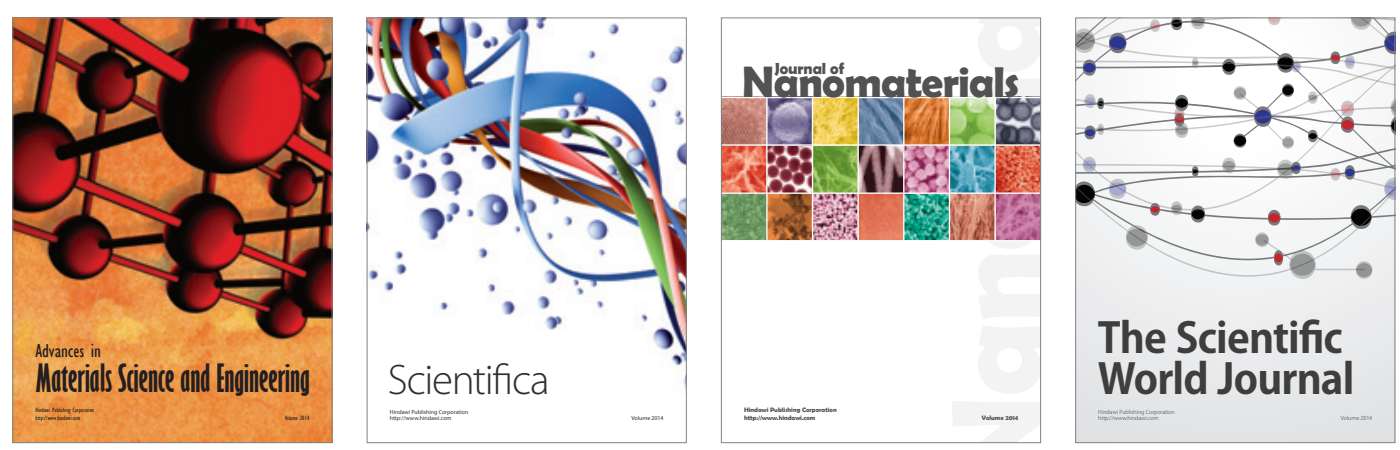

\section{The Scientific World Journal}
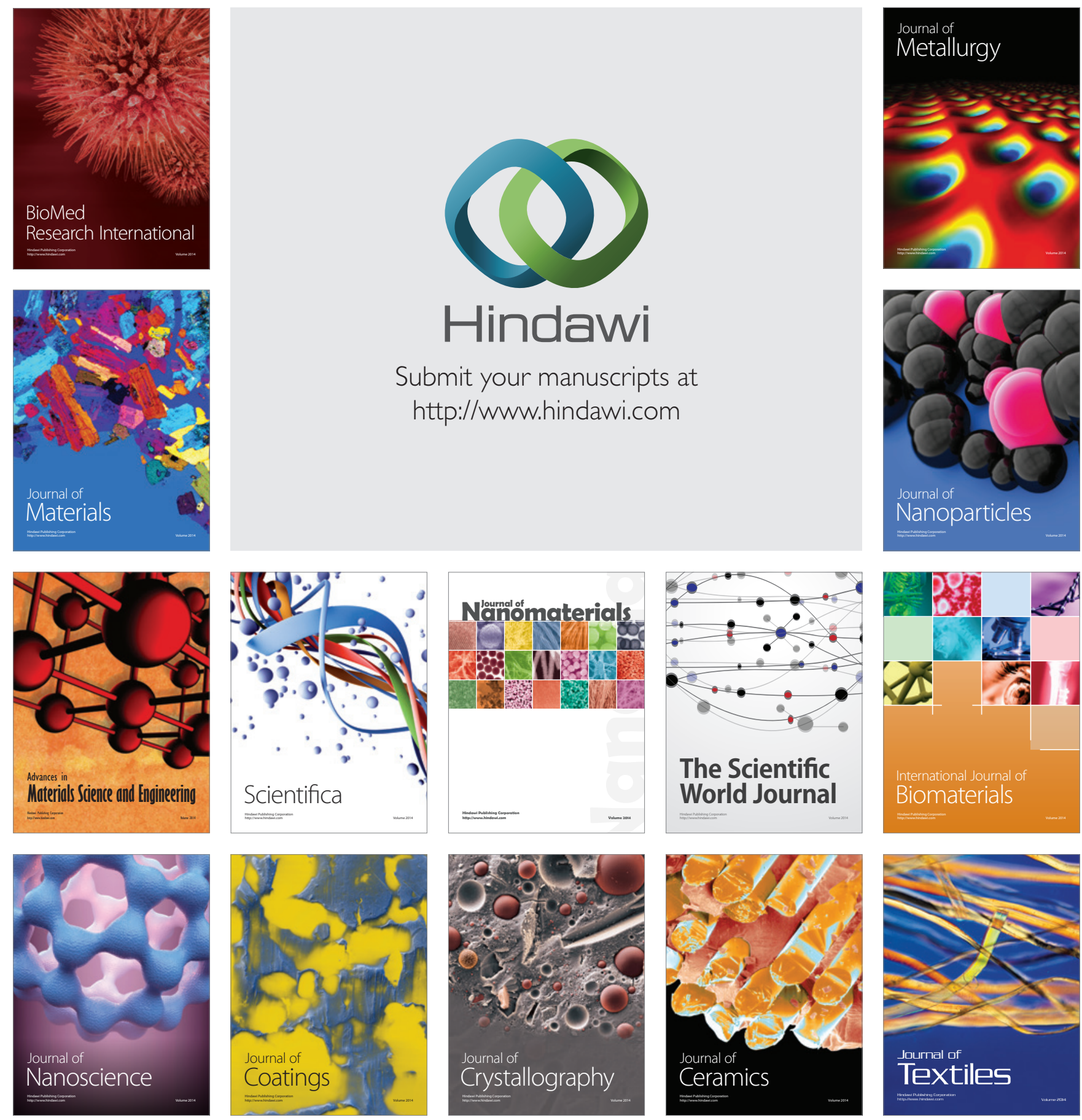